\title{
O CURSO FUNDAMENTAL DA REFORMA FRANCISCO CAMPOS: UM OLHAR SOB AS INSTRUÇÕES PEDAGÓGICAS DO PROGRAMA DE MATEMÁTICA DE 1931
}

\author{
Suely Cristina Silva Souza ${ }^{1}$ \\ Universidade Federal de Sergipe (UFS)
}

\begin{abstract}
RESUMO
O presente trabalho tem por fim apresentar o programa de Matemática do Curso Fundamental e suas Instruções Pedagógicas durante ação da Reforma Francisco Campos no ano de 1931. Tratando-se do estudo de uma disciplina escolar, a investigação foi fruto de uma pesquisa desenvolvida no Núcleo de Pós-Graduação em Educação, da Universidade Federal de Sergipe e obteve auxílio financeiro da Fundação de Apoio à Pesquisa e à Inovação Tecnológica do Estado de Sergipe (FAPITEC/SE). Como resultado, verificou-se que o programa de Matemática implementado pela Reforma Francisco Campos, na aplicação dos seus conteúdos, interagia entre seus ramos, de forma paulatina até a $5^{\mathrm{a}}$ série, atingindo um conjunto. Quanto às instruções pedagógicas, as mesmas foram descritas de forma geral e sem exemplos práticos sobre a fusão das Matemáticas, contudo se apresentavam diferentes daquelas que foram inseridas nos programas do Colégio Pedro II, nos anos de 1929 e 1930.

Palavras-chave: Reforma Francisco Campos; Ensino secundário; Matemática.
\end{abstract}

\section{THE COURSE OF FUNDAMENTAL REFORM FRANCISCO CAMPOS: A LOOK UNDER THE INSTRUCTIONS OF THE EDUCATIONAL PROGRAM IN MATHEMATICS 1931}

\begin{abstract}
This paper aims to present the program of the Course Fundamental Mathematics and its instructions during action Pedagogical Reform Francisco Campos in 1931. In the case study of a school objecto, the investigation was a result of research developed at the Center for Postgraduate Education, Federal University of Sergipe and received financial assistance from the Foundation to Support Research and Technological Innovation of the State of Sergipe (FAPITEC/SE). As a result, it was found that the mathematics program implemented by Francisco Campos Reform in the application of its contents, interacted among its branches, up steadily until the 5th grade, reaching a whole. As for the educational instruction, they were described in general terms and without practical examples on the integration of mathematics, however, were different from those that were inserted in the programs of the College of Pedro II, in the years 1929 and 1930 Keywords: Francisco Campos Reform, Secondary Education, Mathematics.
\end{abstract}

No Brasil, a História da Educação nos revela que desde o século XIX e começo do século XX ocorreram várias tentativas de estruturação do ensino secundário, muitas vezes abandonadas ou radicalmente modificadas, mas que se prolongaram até os anos de 1942. Entre essas tentativas, pode-se considerar a Reforma Francisco Campos como a pioneira na organização desse ensino. 
Implementada por Francisco Luís da Silva Campos (1891-1968) ${ }^{2}$, em 1931, a referida reforma permitiu ao governo federal maior controle da organização curricular e definiu os programas adotados no ensino secundário. Na concepção de Francisco Campos, "o ensino secundário é o de maior importância", "sua finalidade" seria "muito mais ampla" do que o "objetivo estreito de mero preparatório para as faculdades" (ROCHA, 2001, p. 150-151).

As transformações provocadas pela Revolução de 1930, intensamente influenciadas pelas ideias renovadoras travadas durante os anos 20, denominadas de Escola Nova ${ }^{3}$, permitiram a constituição de um novo cenário educacional brasileiro com base nacional, articulado com o sistema central e em prol de uma política nacional de educação.

Frente ao novo regime, o Governo Provisório instalou novos órgãos administrativos, e, entre eles, o Ministério da Educação e Saúde Pública. Criado por meio do Decreto de 14 de novembro de 1930, ao novo Ministério estava incumbido o estudo e o encaminhamento de todos os assuntos referentes ao ensino, bem como aqueles atrelados à saúde pública e à assistência hospitalar. O decreto deliberado também estabelecia que as Instituições, Departamentos e Repartições Públicas, ligados, de algum modo, à área educacional, ficariam a ele vinculados. Seu comando estava em mãos de Francisco Luís da Silva Campos, possuidor de poderes amplos e controladores do setor educacional, que ao assumir o cargo realizou como uma de suas primeiras atribuições a Reforma Francisco Campos, modificando nacionalmente a educação por "um conjunto de seis decretos" (SAVIANI, 2004, p. 31).

1. Decreto n. ${ }^{\circ} 19.850$ - de 11 de abril de 1931:

Cria o Conselho Nacional de Educação.

2. Decreto n..$^{\circ} 19.851$ - de 11 de abril de 1931:

Dispõe sobre a organização do ensino superior no Brasil e adota o regime universitário.

3. Decreto n. ${ }^{\circ} 19.852$ - de 11 de abril de 1931:

Dispõe sobre a organização da Universidade do Rio de Janeiro.

4. Decreto n. ${ }^{\circ} 19.890$ - de 18 de abril de 1931:

Dispõe sobre a organização do ensino secundário.

5. Decreto n..$^{\circ} 20.158$ - de 30 de junho de 1931:

Organiza o ensino comercial, regulamenta a profissão de contador e dá outras providências.

6. Decreto n. ${ }^{\circ} 21.241$ - de 14 de abril de 1932:

Consolida as disposições sobre a organização do Ensino Secundário (SAVIANI, 2004, p. 32).

Entre esses decretos irei destacar a ação do Decreto $n^{\circ}$. 19.890, de 18 de abril de 1931, responsável pela organização do ensino secundário e que somente se consolidou por meio do Decreto $\mathrm{n}^{\circ}$. 21.241, em 4 de abril de 1932. Concordo com Silva (1969), quando diz que:

A reforma de 1931 representou o início de uma nova fase de considerável progresso no sentido da constituição de uma estrutura institucional de ensino secundário não somente adequada à função de preparação básica ao ensino superior, como também orientada para uma finalidade mais compreensiva de preparação do adolescente para sua satisfatória integração a uma sociedade que ia começar a fazer-se mais complexa e dinâmica (SILVA, 1969, p. 285-286). 
No Brasil, até 1931 o ensino secundário não apresentava uma frequência obrigatória; ocorria a "possibilidade de prestar os exames, obter o título de Bacharel e ingressar no ensino superior, independente de ter havido a realização de um curso regular"(VEIGA, 2007, p. 249-250). Por isso, optei em estudar as mudanças ocorridas no ensino secundário durante a Reforma Francisco Campos e sua real finalidade traduzida nas páginas da Exposição de Motivos que a acompanhou:

\begin{abstract}
A finalidade do ensino secundário é de fato, mais ampla do que a que se acostuma atribuir-lhe. Via de regra, o ensino no secundário tem sido considerado entre nós como um simples instrumento de preparação dos candidatos ao ensino superior, desprezando-se, assim, a sua função eminentemente educativa que consiste, precisamente, no desenvolvimento das faculdades de apreciação, de juízo, de critério, essenciais a todos os ramos da atividade humana, e, particularmente, no treino da inteligência em colocar os problemas nos seus termos exatos e procurar as suas soluções adequadas (BRASIL, 1931).
\end{abstract}

Desde o ano de 1925 a duração do curso secundário definia-se em seis anos seriados com o objetivo "de oferecer um preparo geral e fundamental para vida". Neste sentido, o aluno que concluísse integralmente seus estudos recebia "o diploma de bacharel em ciências e letras"; no entanto, aquele que o findasse pelo período cinco anos "tinha direito a realizar os exames vestibulares para qualquer curso superior, suprimidos os exames parcelados de preparatórios" (NUNES, 2000, p. 44).

Até o final dos anos 20 do século XX, no Brasil prevaleceu, para o ingresso ao ensino superior, o sistema de preparatórios e, quando necessários, os exames parcelados que eliminavam a proposta de seriação do curso secundário. Para tanto, os estudos secundários não passavam de um simples curso de passagem aos superiores, destituído de características educativas, apresentando-se apenas como uma finalidade utilitária.

Nesta época, o ensino secundário brasileiro possuía uma função educativa por meio de um curso regular. Contudo, a implementação da Reforma Francisco Campos no ano de 1931, reafirmou essa particularidade como uma finalidade formativa, conforme sua exposição de motivos:

\begin{abstract}
A finalidade exclusiva do ensino secundário não há de ser a matrícula nos cursos superiores; o seu fim, pelo contrário, deve ser formação do homem para todos os grandes setores da atividade nacional, constituindo no seu espírito todo o sistema de hábitos, atitudes e comportamento que o habilitem a viver por si mesmo e a tomar, em qualquer situação, as decisões mais convenientes e mais seguras (BRASIL, 1931).
\end{abstract}

A Reforma Francisco Campos organizou o ensino secundário em dois ciclos, a partir de um currículo seriado, com frequência obrigatória, ministrado por professores diplomados mediante concurso promovido pelo Ministério da Educação e Saúde Pública e inspecionado oficialmente quando o estabelecimento fosse equiparado ao Colégio Pedro II.

Os dois ciclos eram divididos em Fundamental, com duração de 5 anos; e outro Complementar, de 2 anos. Para ingresso nos estudos secundários o pretendente deveria fazer inscrição mediante requerimento, apresentando no seu ato comprovação de idade de 11 anos, filiação, naturalização e residência. Além do atestado de vacinação antivariólica, 
recibo de taxa de pagamento de inscrição para prestar exame de admissão na segunda quinzena de fevereiro em um único estabelecimento. $\mathrm{O}$ exame realizar-se-ia por meio de provas escritas e orais. As primeiras versariam sobre Português (redação e ditado) e outra de Aritmética (Cálculo Elementar). Na aplicação das provas orais ainda se cobrava do aluno o conhecimento dessas disciplinas, como também as noções de Geografia, História do Brasil e Ciências Naturais. As avaliações seriam reguladas e julgadas através do Departamento Nacional do Ensino.

O Ciclo Fundamental possuía caráter obrigatório, de formação básica, seriado em cinco anos para o ingresso nas escolas superiores, e seu currículo apresentava equilíbrio entre os estudos literários e científicos constituído pelas disciplinas Português, Francês, Inglês, Latim, Alemão, História, Geografia, Matemática, Ciências Físicas e Naturais, Física, Química, História Natural, Desenho e Música na modalidade Canto Orfeônico, conforme o Art. $3^{\circ}$ do Decreto de 1932.

Art. $3^{\circ}$ Constituirão o curso Fundamental as matérias abaixo indicadas, distribuídas em cinco anos, de acordo com a seguinte seriação:

$1^{a}$ série: Português - Francês - História da Civilização - Geografia Matemática - Ciências Físicas e Naturais - Desenho - Música (Canto Orfeônico).

$2^{\mathrm{a}}$ série: Português - Francês - Inglês - História da Civilização - Geografia - Matemática - Ciências Físicas e Naturais - Desenho - Música (Canto Orfeônico).

$3^{\mathrm{a}}$ série: Português - Francês - Inglês - História da Civilização - Geografia - Matemática - Física - Química - História Natural - Desenho - Música (Canto Orfeônico).

$4^{\mathrm{a}}$ série: Português - Francês - Inglês - Latim - Alemão (facultativo) História da Civilização - Geografia - Matemática - Física - Química História Natural - Desenho.

$5^{\mathrm{a}}$ série: Português - Latim - Alemão (facultativo) - História da Civilização - Geografia - Matemática - Física - Química - História Natural - Desenho (BRASIL, 1931).

O Ciclo Complementar, de caráter propedêutico, ou seja, um curso preparatório conforme grau de especialização para ingresso nas Faculdades de Direito, Ciências Médicas e Engenharia, em dois anos, com um currículo constituído pelas disciplinas: Alemão ou Inglês, Latim, Literatura, Geografia, Geofísica ou Cosmografia, História da Civilização, Matemática, Física, Química, História Natural, Biologia Geral, Higiene, Psicologia e Lógica, Sociologia, Noções de Economia e Estatística, História da Filosofia e Desenho, de acordo com o Art. $5^{\circ}$ do Decreto de 1932.

Art. $5^{\circ}$ Para os candidatos à matrícula no curso Jurídico são disciplinas obrigatórias:

$1^{a}$ série: Latim - Literatura - História da Civilização - Noções de Economia e Estatística - Biologia Geral - Psicologia e Lógica.

$2^{a}$ série Latim - Literatura - Geografia - Higiene - Sociologia - História da Filosofia.

Art. $6^{\circ}$ Para os candidatos à matrícula nos cursos de Medicina, Farmácia e Odontologia são disciplinas obrigatórias:

$1^{a}$ série: Alemão ou Inglês - Matemática - Física - Química - História Natural - Psicologia e Lógica. 


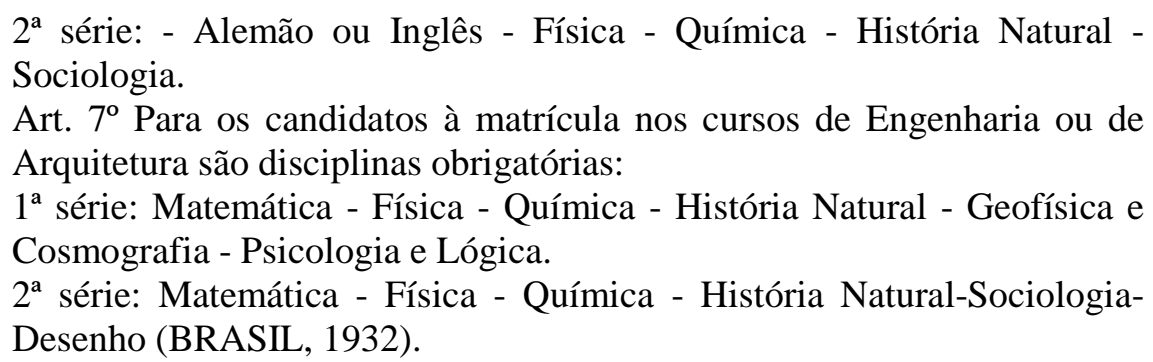

O programa de ensino deveria ser organizado e ministrado de acordo com a duração do ano letivo, do método de ensino, expedidos pelo Ministério da Educação e Saúde Pública e revistos, de três em três anos, por uma comissão designada pelo ministro. Além das disciplinas citadas, esses estabelecimentos de ensino, obrigatoriamente, ofereciam exercícios de Educação Física em todas as classes, caso contrário os militares garantiam esses ensinamentos.

Os exercícios de educação física deveriam ser realizados diariamente, com duração de 30 a 45 minutos, sendo aconselhada na Portaria a adoção das 'normas e diretrizes' do Centro de Educação Física do Exército. Mas, enquanto o Ministério da Educação e saúde limita-se a introduzir a obrigatoriedade da educação física na legislação educacional, os militares procuram estabelecer bases solidas para garantir o seu predomínio nesta área (HORTA, 1994, p. 66).

O aluno, quando admitido, não poderia ter sua frequência escolar igual ou superior a três quartos do total de aulas de cada série, visto que cada turma não teria menos de $20 \mathrm{ou}$ mais de 28 horas de aula por semana, excluindo desse tempo os exercícios físicos e as aulas de Música. O diretor organizava esse cronograma antes de iniciar os cursos, e determinava como duração de cada aula o tempo de 50 minutos, com intervalo entre as aulas: um intervalo obrigatório de 10 minutos.

Como requisito da seleção do corpo docente, os candidatos deveriam possuir formação na Faculdade de Educação, Ciências e Letras do Rio de Janeiro, no entanto o provimento do cargo dar-se-ia através de concurso de título e provas. Cabe aqui ressaltar que, a lei de reorganização da Universidade do Rio de Janeiro, de 1931, previa a criação de uma Faculdade de Educação, Ciências e Letras. No entanto, apenas no ano de 1939 foi possível criar "uma unidade universitária correspondente àquela prevista por Francisco Campos, com objetivos de desenvolvimento cultural desinteressado, fora dos moldes tradicionais das Faculdades de Medicina, Direito e Engenharia", a fim de "atender as necessidades de preparo dos professores para o ensino secundário": a Faculdade Nacional de Filosofia, vinculada à Universidade do Brasil, no Rio de Janeiro (PRADO, 2003, 102).

Assim, as outras Faculdades de Filosofia passariam a ministrar seus cursos por meio da adoção do currículo e seriação prescritos pela Faculdade Nacional.

Neste sentido, a nomeação de cada professor seria por 10 anos e com direito à recondução, através de novo concurso. Além dos professores catedráticos havia os auxiliares de ensino, nomeados pelo diretor da secção de cada disciplina do Colégio Pedro II após prestarem concurso, entre outras atribuições, mediante o Art. 19 do Decreto de 1932. 
Art. 19. Os auxiliares de ensino serão nomeados pelo diretor da secção do Colégio Pedro II, a que pertencerem às disciplinas a cujo ensino devam prestar concurso.

$\S 1^{\circ}$ As nomeações dos auxiliares de ensino, nos termos deste artigo, serão feitas mediante indicação dos professores catedráticos com os quais devam cooperar e de cuja confiança dependa a respectiva permanência no cargo.

$\S 2^{\circ} \mathrm{O}$ número dos auxiliares de ensino variará de acordo com as necessidades didáticas das disciplinas, principalmente das que exijam trabalhos de gabinete ou de laboratório.

$\S 3^{\circ}$ Aos auxiliares de ensino caberão atribuições, prerrogativas e vencimentos que serão discriminados no regulamento do Colégio Pedro II (BRASIL, 1932).

Ao longo do ano letivo, a avaliação dos alunos se efetivava por meio de arguições, trabalhos práticos e provas escritas parciais, para, então, estimar-se notas graduadas de zero a dez. A cada mês, a partir de abril, o professor de cada disciplina atribuía ao aluno uma nota referente a uma arguição oral ou a trabalhos práticos, de modo a produzir uma média mensal, que quando computada à média, mês a mês, constituiria a média anual. Aplicavam-se anualmente quatro provas parciais de cada disciplina em sua respectiva classe, de modo que a totalidade das quatro provas escritas constituía a sua nota final; e, quando não comparecidas ou assinadas, o aluno teria a nota zero. Avaliavam-se, a cada final de período letivo, os trabalhos de laboratório dos alunos, por meio de provas finais, na modalidade oral ou prático-oral, sobre todo conteúdo da matéria do programa. Considerava-se aprovado o aluno que obtivesse a nota final igual ou superior a três, em cada disciplina, ou média equivalente ou superior a cinco, no conjunto das disciplinas da série.

O serviço de inspeção do ensino secundário foi criado pelo Departamento Nacional do Ensino, constituído pelos inspetores de estabelecimento, inspetores regionais e quatro inspetores assistentes. Nomeados por concursos, seriam escolhidos facultativamente pela inspetoria ou pelo estabelecimento de ensino para exercerem suas respectivas funções. Suas atribuições tornavam o sistema de inspeção rígido e muitas vezes provocavam nos professores e alunos uma determinada pressão psicológica

Assim, a Reforma Francisco Campos permitiu que seu processo de institucionalização fosse reafirmado por meio da padronização das escolas secundárias, mediante "manutenção do sistema de equiparação e de inspeção federal" (SOUZA, 2008, p. 150). Neste sentido, a referida reforma provocou mudanças significativas no contexto social da época, diante da nova concepção de escola secundária que se concebia.

Ao estudar a Reforma Francisco Campos, principalmente os Decretos no .19 .890 e $\mathrm{n}^{\mathrm{o}}$. 21.241, que traçaram novas diretrizes quanto à organização do ensino secundário e à inovação desse sistema escolar, foi possível perceber a instalação de uma nova realidade sócio-política. A necessidade de elevar a situação econômica, política e social do país fez com que o Governo, pelo menos teoricamente, implantasse algumas soluções para os problemas educacionais, atreladas à verdadeira finalidade do ensino.

Antes da Reforma Campos, no Brasil, somente em raros documentos oficiais e em poucas peças da literatura pedagógicas expressou-se tão nitidamente a necessidade de partir-se do objetivo do ensino secundário 
para chegar-se a determinação do seu currículo e seus métodos (SILVA, 1969, p. 287-288).

Por isso, a Reforma Francisco Campos teve mérito em organizar os estudos secundários nos estabelecimentos de ensino apropriados, uma vez que apresentava um programa de ensino de caráter obrigatório em todo país, ministrado e equiparado ao Colégio Pedro II, no ano de 1931. Portanto, as ideias circulavam dentro do território nacional rumo ao progresso, embora a reforma apresentasse algumas deficiências. Nesse ponto, compactua-se com Rocha (2001, p. 162), quando afirma que entre suas falhas consta o fato "de não ter resolvido a questão da demanda pelo ensino secundário na década de 1930, pois manteve o seu caráter elitista [...]", apropriando-se apenas dos ideais liberais escolanovistas.

Ainda nas palavras de Rocha (2001), o ensino secundário se dividiu em duas fases: "a primeira, com a função de formar o cidadão para viver em um regime democrático e a segunda, com o objetivo de preparar os alunos, interessados em continuar os estudos, para o ingresso nos cursos superiores existentes". No entanto, a segunda fase não correspondia à finalidade idealizada para os Cursos Complementares, pois "ao invés de o ensino secundário ser estendido para sete anos, o que ocorreu, na realidade, foi um acréscimo de dois anos nos cursos superiores, ficando o secundário estruturado em apenas cinco" (ROCHA, 2001, p. 156-157).

Conforme Otone e Silva (2006, p. 45), "uma vez que a reforma se aplicava, em 1931, aos alunos da $1^{a}$ série do Ensino Secundário", os mesmos chegariam "sem repetência à quinta série, em 1935; assim, presumi-se que o primeiro ano do curso Complementar só passaria a vigorar a partir de 1936". Logo, o processo de admissão aos cursos superiores "tornou-se obrigatório em 1938", após conclusão das turmas iniciais do Curso Complementar (ROCHA, 2001, p. 157). Essas colocações fazem sentido quando se analisa o desenvolvimento do curso secundário durante a Reforma Francisco Campos.

Mesmo sendo uma grande reforma, problemas como sua alta seletividade, rigoroso sistema de avaliação e normas legitimavam a centralidade dos conhecimentos e reafirmavam o seu caráter elitista, visto que "a escola secundaria continuava sendo símbolo de distinção cultural e o seu papel de integração nacional foi reforçado" por meio dos programas das disciplinas, métodos de ensino e, principalmente, pela inspeção escolar (SOUZA, 2008, p. 164).

Esses instrumentos controladores podem ser evidenciados nas palavras de Moreira (1990), quando diz que:

[...] rigidamente prescritos, particularmente para o ensino secundário. Um sistema bastante centralizado foi instalado, com um razoável número de instrumentos controladores. Inspetores federais, por exemplo, foram encarregados de visitar escolas e inspecionar e controlar diretores, professores e alunos (MOREIRA, 1990, p. 97).

Autores como Rocha (2001), Dassie (2001), Souza (2008) e Silva (1969) afirmam que a Reforma Francisco Campos adotou um currículo enciclopédico, pelo extenso número de conteúdos apresentados nos programas de ensino. Nesta época, a classe mais favorecida constituía a única camada social capaz de absorver toda cultura geral nos cinco anos do ensino secundário; fato que pode ser confirmado nas palavras de Nunes (2000), quando diz que: 
O seu currículo continuou enciclopédico e, no ciclo fundamental, os estudos científicos apresentavam, diferentemente da Reforma Benjamin Constant, na qual houve o predomínio das matemáticas, o domínio das ciências físicas e naturais. O curso complementar de currículo diferenciado quanto à destinação dos alunos também assumia ares de um enciclopedismo especializado (NUNES, 2000, p. 44).

Também se corrobora com Souza (2008, p. 153), no que diz respeito à deficiência da reforma quanto à falta de "articulação entre o secundário e os outros ramos do ensino médio". Esse problema provocou dificuldades no andamento educacional, pois o crescimento industrial ocorrido depois dos anos de 1930 aumentou a procura pela escola secundária, que apenas possuía flexibilidade com o ensino comercial e não com os cursos profissionalizantes. Naquele momento os "cursos profissionais" satisfaziam as necessidades imediatas do país, pela inclusão de conhecimentos de aplicações técnicas e não apenas por meio de conteúdos modernos.

Portanto, na busca de soluções para as novas demandas sociais, o ensino secundário reformulou-se, mais uma vez, nos anos de 1942, pela então chamada Reforma de Capanema.

Desse modo, a Reforma Francisco Campos foi implementada em todas as escolas públicas e privadas do Brasil. Seu curso seriado passaria a ser ministrado em 7 anos, sendo os cinco primeiros destinados ao Curso Fundamental e os 2 anos para preparação ao ensino superior, também o chamado Curso Complementar.

Art. $1^{\circ} \mathrm{O}$ ensino secundário oficialmente reconhecido, será ministrado no Colégio Pedro II e em estabelecimentos sob regime de inspeção oficial.

Art. $2^{\circ} \mathrm{O}$ ensino secundário compreenderá dois cursos seriados: fundamental e complementar (BRASIL, 1931).

A Congregação do Colégio Pedro II elaborava as propostas de mudanças e as revisões periódicas dos programas de ensino:

Art. 10. Os programas do ensino secundário, bem como as instruções sobre os métodos de ensino serão expedidos pelo Ministério da Educação e Saúde Pública e revistos, de três em três anos, por uma comissão designada pelo ministro e à qual serão submetidas às propostas elaboradas pela Congregação do Colégio Pedro II (BRASIL, 1931).

O programa de ensino de Matemática ficou a cargo do professor Euclides de Medeiros Guimarães Roxo (1890-1950) ${ }^{4}$, que "aproveitou a oportunidade para implementar em todo país as idéias modernizadoras que, desde o início do século, já vinham sendo disseminadas nos países 'civilizados"'(ROCHA, 2001, p. 166).

No Brasil, nos anos de 1925 a 1930, a escola secundaria também se organizava através de exames preparatórios, período obrigatório de seriação do ensino para acesso aos cursos superiores. Na realização desses exames os conteúdos a serem estudados eram divulgados pelo Diário Oficial. Nesses tempos de preparatórios as Matemáticas contemplavam os exames de Aritmética, Álgebra, Geometria e Trigonometria. O aluno aprovado estudaria seus ramos nos quatro primeiros anos, do total de seis anos que eram obrigatórios. Sendo assim, "a Aritmética era ministrada no primeiro e segundo ano do 
secundário, a Álgebra era estudada no terceiro ano e a Geometria, que incluía a Trigonometria, no quarto ano" (ALVAREZ, 2004, p. 5).

Implementada nos anos de 1925, a Reforma de Rocha Vaz não permitia que os alunos estudassem conteúdos matemáticos diferenciados "no mesmo ano, só a Aritmética não sofreu alterações, a Álgebra e a Geometria eram estudadas cada uma durante o ano e em anos diferentes com os mesmos conteúdos", reforçando o caráter independente desses ramos (MIRANDA, 2003, p. 66-68).

Assim, o ensino seriado nos liceus, nos colégios particulares, reforçava o caráter separado dos ramos matemáticos. A seriação era função dos exames parcelados e o ensino era ministrado na ordem em que os alunos deveriam prestar os exames: aritmética, álgebra, geometria e trigonometria. Os pontos de cada disciplina, referência dos exames, organizavam os textos didáticos e o ensino da matemática (VALENTE, 2004b, p. 82).

No ano de 1927 iniciaram-se discussões acerca da modificação do programa de ensino ${ }^{5}$ do Colégio Pedro II, mas em julho de 1928 a sua "Congregação propôs ao Conselho Nacional de Ensino mudanças no ensino de Matemática e na seriação do curso secundário para cinco anos, seguido de mais um ano que seria o curso complementar" (ALVAREZ, 2004, p. 5-6).

Com a chegada do ano de 1929, aumenta-se a procura pela escola secundária, já que para o acesso ao ensino superior o aluno, obrigatoriamente, depois do primário, deveria ingressar na primeira série do curso secundário. Nesta época a educação era responsável pela aceleração da modernização, modificando toda a organização 'didáticopedagógica' "para a nova clientela e as novas condições de trabalho escolar", inclusive para o ensino de matemática (VALENTE, 2004b, p. 82).

Essas modificações contemplam a proposta de unificação da Aritmética, Álgebra e Geometria em uma só disciplina, com as contribuições de Euclides de Medeiros Guimarães Roxo, no Colégio Pedro II, no ano de 1929.

Em 26 de julho de 1928, impulsionado por movimentos internacionais de renovação do ensino de Matemática, Euclides Roxo propôs uma modificação curricular e metodológica no curso seriado do ensino secundário no Colégio Pedro II, a qual foi regulamentada pelo Decreto de 15 de janeiro de 1929. Essas ideias estavam baseadas na reforma alemã de Felix Klein, veiculadas, principalmente, pelo Internationale Mathematische Unterrichtskommission (IMUK) e pela Commission Internationale de l'Enseignement Mathématique (CIEM), cuja "tarefa atribuída ao comitê era restrita em diversos aspectos [...]. O comitê deveria preparar relatórios a respeito do estado da instrução matemática nas escolas secundárias dos países mais desenvolvidos" (VALENTE, 2004a, p. 18).

A proposta apresentada por Euclides Roxo abordava a criação da disciplina Matemática, através da fusão das ramificações das Matemáticas em uma só disciplina, de acordo com as características defendidas pelo Movimento Internacional para a modernização do ensino da Matemática. A nova disciplina ocuparia os quatro primeiros anos do curso secundário, e o sexto ano como curso complementar ${ }^{6}$; seu programa de estudos incluiria, desde o primeiro ano, conteúdos correlatos à Geometria, Álgebra e Aritmética. 
Como objetivo, a reestruturação dos ensinamentos matemáticos nos secundários pretendia implementar, gradualmente, os programas de Matemática, conforme dissertou Rocha (2001) em seu trabalho, quando apresentou o relato redigido por Roxo ao Departamento Nacional de Ensino:

\begin{abstract}
Na cadeira de Matemática fez-se completa renovação, de acordo com as atuais diretivas pedagógicas dominantes, quanto a essa disciplina, em quase todos os países civilizados. Adotados somente para o primeiro ano em 1929, será a nova orientação estendida , em 1930 , ao segundo ano, e assim sucessivamente, a todos os anos do curso. Em consequiência dessa reforma, deverão os alunos, ao invés de um exame final de Aritmética, outro de Álgebra e um terceiro de Geometria, fazer, no quarto ano, um exame final único de Matemática, sendo os do $1^{\circ}, 2^{\circ}$ e $3^{\circ}$ de simples promoção (ROXO apud ROCHA, 2001, p. 33).
\end{abstract}

Por esse relato, percebeu-se que a reforma homologada pelo Decreto $\mathrm{n}^{\mathrm{o}}$. 18.564 implantava, gradativamente, tais mudanças, ou seja, em 1929 o primeiro ano do curso seria alterado, o segundo em 1930 e assim sucessivamente, para que todas as séries dos secundários seguissem as novas orientações.

Contudo, "as grandes modificações do ensino de Matemática não estavam resumidas na disposição de seu conteúdo programático" e sim nas "novas orientações pedagógicas inscritas em instruções, as quais objetivavam explicar como os conteúdos deveriam ser ensinados", tanto para o ano de 1929 como para o de 1930 (ALVAREZ, 2004, p. 6-7).

Neste mesmo período Euclides Roxo escreveu a coleção Curso de Matemática Elementar, sendo, o primeiro volume, publicado em 1929, cujas Instruções Pedagógicas provinham de "outros países como França, Alemanha, Itália, Suíça, Inglaterra, Estados Unidos, Argentina por influência de Félix Klein” (MIRANDA, 2003, p. 73). A coleção instituiu uma inovação na literatura didática para o ensino de Matemática no Brasil como a primeira tentativa de renovação dos métodos de ensino no curso secundário, conforme o movimento de reforma, cujas diretivas estavam de acordo com as três tendências elaboradas por Klein.

\title{
1- TORNAR ESSENCIALMENTE PREDOMINANTE O PONTO DE VISTA PSICOLÓGICO [...] \\ 2 - NA ESCOLHA DA MATÉRIA A ENSINAR TER EM VISTA AS APLICAÇÕES DA MATEMÁTICA AO CONJUNTO DE OUTRAS DISCIPLINAS [...] \\ 3- SUBORDINAR O ENSINO DA MATEMÁTICA A FINALIDADE DA ESCOLA MODERNA [...] (DASSIE, 2001, p. 5).
}

Essas três tendências permitiram produzir outras peculiaridades que se envolveram e se findaram.

1) A fusão da Aritmética, Álgebra e Geometria (incluída a Trigonometria). A esse respeito, Klein dizia: "Não quero dizer que essas partes devam ser completamente fundidas, mas não devem ser tão separadas como sucede hoje nas escolas, contra o que é natural".

2) introdução precoce da noção de função, que, para Klein, é o âmago do moderno movimento da reforma apresentada sob forma geométrica e 
expressa pelas representações gráficas, das quais Klein diz: "penetram não somente através de grande literatura moderna das ciências exatas, mas, pode-se dizer, surgem em todas as cogitações da vida atual".

3) Abandono, em parte, da rígida didática de Euclides ("die starre euklidische Manier") com a introdução da idéia da mobilidade de cada figura, por meio da qual, em cada caso particular, tornar-se compreensível o caráter geral da geometria.

4) Introdução, desde de cedo, de noções de coordenadas e de geometria analítica, que "é acessível à compreensão dos meninos desde as primeiras séries e, por isso, deveria penetrarem todo o ensino da Matemática" ao invés de, como se fazia naquela época,"sobrepor-se como uma nova construção à parte, ao estudo já concluído das Geometria Elementar".

5) Introdução de noções de cálculo diferencial e integral, apoiada de modo preponderante em métodos geométricos e, portanto, intuitivos.

6) Maior desenvolvimento do ensino do desenho projetivo e da perspectiva, ainda em conexão como estudo da Geometria Elementar.

7) A introdução de recursos de laboratórios ( constituindo que os norteamericanos chamam de "laboraty methods", como sejam regras graduadas , compassos, instrumentos de medir ângulos (prancheta, trânsito, etc), papel milimetrado, esferas negras, balanças, termômetros, alavancas, planímetros, polias, aparelhos de demonstração, figuras e sólidos de vidros, de fios de seda etc).

8) Finalmente, um principio quer presidia a todos anteriores, o do método histórico no desenvolvimento da Matemática, principio pedagógico de ordem geral, por todos reconhecidos, mas respeitado (MIRANDA, 2003, p. 75).

Assim, o ministro Francisco Campos reformulou o ensino secundário, comercial e superior, além de acatar as ideias renovadoras de Euclides Roxo para o ensino de Matemática. Segundo Souza (2008), o ensino de Matemática possuía uma estrutura curricular de acordo com a Reforma Francisco Campos, apresentando em cada série uma ementa de conteúdos para cada matéria, instruções e finalidades inerentes às inovações pedagógicas.

O ensino da Matemática fundamentava-se também em princípios pedagógicos modernos. Visando ao desenvolvimento de habilidades intelectuais como o rigor no raciocínio, a capacidade de resolver e agir, com presteza e atenção, a faculdade de compreensão e de análise das relações quantitativas e espaciais, o ensino da disciplina deveria acostumar o aluno à prática dos cálculos mentais, habituá-lo ao emprego, com segurança, das idéias e conceitos que estruturam o pensamento quantitativo. Para atingir tais finalidades, deveriam os professores empregar métodos ativos e a resolução de problemas, renunciando completamente "à prática de memorização sem raciocínio, ao enunciado abusivo de definições e regras e ao estudo sistemático das demonstrações já feitas". A unidade da matéria seria garantida pela noção de função desenvolvida nos conteúdos de Aritmética, Álgebra e Geometria (SOUZA, 2008, p. 158).

Nas palavras de Rocha (2001), Euclides Roxo se aproveitou dos postos que ocupava como Diretor do Colégio Pedro II e membro do Conselho Nacional de Ensino, 
permitindo, naquele momento, livre acesso ao ministro Francisco Campos, bem como para estender a todo país novidades implantadas, progressivamente, na escola padrão.

[...] O professor Euclides Roxo tirou proveito da posição que ocupava na estrutura educacional do país, a qual lhe proporcionava condições de fazer valer suas idéias, e implementou integralmente, pelo menos na lei, 'de cima para baixo' e sem discussões prévias, todas as inovações defendidas por Felix Klein [...] ( ROCHA, 2001, p. 199).

Essas inovações provinham das apropriações de "estudos e resultados de pesquisas internacionais" realizados por Roxo, posteriormente compilados e publicados em "vários livros didáticos", destinados a guiar "professores e alunos no ensino aprendizagem da Matemática Nova" (TAVARES, 2002, p. 99).

Neste ponto considero as reflexões apresentadas por Bourdieu (1983), quando discute sobre as relações provindas de um determinado capital, o simbólico, que entre outras determinações possibilita que o indivíduo articule o seu prestígio e a boa reputação num campo específico ou na sociedade em geral em prol de reconhecimentos. Assim, os agentes se submetiam ao poder de dominação ideológica para se legitimarem no espaço social a que pertenciam, e a produção desses livros seria um dos caminhos.

Portanto, a primeira versão da obra Curso de Matemática Elementar comportava "todo o programa do Colégio Pedro II de 1929", além de ser "totalmente diferente das demais obras existentes, pela apropriação que o professor brasileiro fez do ideário do movimento internacional de reforma do ensino da matemática" (WERNECK, 2003, p. 8586).

Sem dúvida, o protagonista do novo programa e instruções matemáticas para a Reforma Francisco Campos foi Euclides Roxo. Seu ideário se estendeu até os anos iniciais da década de 1940, quando contribuiu na formulação da Reforma de Capanema, apesar de não ser o único partícipe da elaboração desse novo programa.

Em 1942, a elaboração dos programas de todas das disciplinas ficou sob a responsabilidade de uma comissão designada pelo ministério da educação. Outra observação a ser feita é que a discussão sob tal elaboração envolveu pessoas que não faziam parte da citada comissão. Dessa forma, Euclides Roxo não foi o único protagonista na história dessa disciplina (DASSIE, 2001, p. 158-159).

Em suma, a Reforma Francisco Campos impôs em todo território nacional a proposta elaborada por Euclides Roxo, principalmente ao interligar numa só disciplina todos os ramos das Matemáticas, reestruturar todo currículo através do conceito de função e introduzir noções de cálculo diferencial e integral nos estudos secundários.

De todo modo, essa etapa histórica do trajeto da disciplina escolar matemática resulta no surgimento das matemáticas unificadas, ao menos formalmente, no âmbito do primeiro currículo nacional, sob o titulo de Matemática. Não mais existirão, a partir daí, as cátedras separadas de Aritmética e Álgebra, Geometria e Trigonometria. A disciplina matemática passará por uma certa estabilidade em, seus programas, livros didáticos e discussões pedagógicas sobre o seu ensino. Esse panorama 
mudará com os novos tempos tecnológicos que surgirão a partir da segunda metade do século XX (VALENTE, 2003, p. 247).

Por fim, essa reforma respondia às finalidades dos ideais escolanovistas. Entretanto, mesmo com todas as inovações presentes, continuou formando elites num sistema fechado e sem nenhuma articulação entre os ramos do ensino secundário com os cursos profissionalizantes. Quanto ao ensino de Matemática brasileiro, o estudo dos reflexos da proposta de Euclides Roxo não pode ser entendido como único "principalmente, pelo fato de, 11 anos depois" (ROCHA 2001, p. 202), implementar-se outro grande projeto: a Reforma Gustavo Capanema, embora seja outra história.

Neste sentido, faz-se oportuno, nesse artigo, relatar a história do ensino de Matemática do Colégio Pedro II, já que a instituição representava um modelo ${ }^{7}$ educacional para as demais escolas secundárias. Porém, a síntese dessas análises deve ser concebida "como parte integrante da história da matemática e da história da sociedade", cuja articulação permite estudar a história de um sistema de ensino e, assim, "contribuir para a educação matemática", além de descrever com mais "precisão o processo de desenvolvimento" dessa disciplina (TAVARES, 2002, p. 13).

Nas palavras de Chervel (1990, p. 179), disciplina escolar define-se como aquilo que se ensina. Assim, os conteúdos matemáticos programados para um nível escolar específico apropriam-se do conceito de "disciplina" ou "ginástica intelectual" como "uma matéria de ensino suscetível de servir ao exercício intelectual". Embora o termo surgisse tardiamente no ensino secundário, o autor nos revela suas causas:

Uma educação que fosse fundamentalmente matemática ou científica não deveria ser, antes do começo do século XX, plenamente reconhecida como uma verdadeira formação de espírito. É somente quando a evolução da sociedade e dos espíritos permite contrapor a disciplina literária uma disciplina científica que se faz sentir a necessidade de um termo genérico (CHERVEL, 1990, p. 179-180).

A defesa da disciplina escolar como uma entidade autônoma epistemologicamente, leva em consideração as relações intrínsecas de poder da escola. Para tanto, a escola deve ser concebida "como uma instituição que, embora obedeça a uma lógica particular e específica da qual participam vários agentes, tanto internos como externos, deve ser considerada como lugar de produção de um saber próprio" (BITTENCOURT, 2004, p. 3839).

Concorda-se com a autora, quando afirma que as disciplinas escolares constituem uma parte significativa da cultura escolar, possibilitando entender as relações com a cultura geral da sociedade. Assim, conteúdos e métodos não podem ser considerados meras adaptações dos conhecimentos produzidos exteriormente, mesmo quando relacionados com outros saberes ou ciências de referência ${ }^{8}$.

A seleção dos conteúdos escolares, por conseguinte, depende essencialmente de finalidades específicas e assim não decorre apenas dos objetivos das ciências de referência, mas de um complexo sistema e valores e de interesses próprios da escola e do papel por ela desempenhado na sociedade letrada e moderna (BITTENCOURT, 2004, p. 39). 
Nessa perspectiva, a pesquisa em questão trata das inovações matemáticas presentes na educação secundária. Entretanto, abordou-se aqui o Curso Fundamental por melhor caracterizar as nuances desse ensino, já que os Cursos Complementares constituíam a parte inicial dos cursos superiores.

Também não cabe aqui analisar, nem ao menos questionar, a incumbência ou não dos tais conteúdos matemáticos do curso secundário, mas apresentar o programa de Matemática do Curso Fundamental e suas Instruções Pedagógicas durante ação da Reforma Francisco Campos no ano de 1931.

Durante a reforma as aulas de Matemática passaram a ser ministradas em todo Ciclo Fundamental. Cada série contemplava uma carga de três horas e seus conteúdos se destinavam a cada nível escolar. O trabalho de Rocha (2001), afirma que os conteúdos das $1^{\mathrm{a}}$ e $2^{\mathrm{a}}$ séries não apresentaram mudanças expressivas. Segundo o autor, o programa de Matemática do Curso Fundamental da Reforma Francisco Campos conservou o ideário inovador da proposta de Euclides Roxo implantado no Colégio Pedro II desde o ano de 1930.

Esses dados podem ser verificados nos programas de ensino reunidos e publicados por Vechia e Lorenz (1998), para a disciplina Matemática:

\section{PRIMEIRA SÉRIE}

3 horas

\section{I - Iniciação geométrica}

Principais noções sôbre formas geométricas.

Área do quadrado, retângulo, paralelogramo, triângulo e trapézio; circunferência e área do circulo.

Volumes do paralelepípedo retângulo, do cubo, do prisma triangular, do cilindro e do cone circular (retos). Fórmulas.

\section{II - Aritmética}

Prática das operações fundamentais. Cálculo abreviado. Exercício de cálculo mental.

Noção de múltiplo e de divisor. Caracteres de divisibilidade.

Decomposição em fatores primos; aplicação ao m. d. c. e ao m. m. c.

Frações ordinárias e decimais. Operações com as frações. Explicação objetiva pelo fracionamento de objetos ou de grandezas geométricas.

Sistema métrico decimal. Prática das medidas de comprimento, superfície, volume e peso.

Sistema inglês de pesos e medidas.

Quadrado e raiz quadrada de números inteiros e decimais; aproximação no cálculo da raiz.

Traçado de gráficos.

\section{III - Álgebra}

Símbolos algébricos; fórmulas; noção de expoente.

Números relativos ou qualificados. Operações. Explicação objetiva das regras dos sinais.

Cálculo do valor numérico de monômios e polinômios. Redução de termos semelhantes; adição e subtração.

Multiplicação de monômios e polinômios, em casos simples. Explicação objetiva pela consideração de áreas.

Potências de monômios. Quadrado de um binômio.

Primeira noção de equação com uma incógnita; resolução de problemas numéricos simples. 


\section{SEGUNDA SÉRIE}

3 horas

\section{I - Iniciação geométrica}

Noção de ângulo e de rotação; ângulos adjacentes, complementares, suplementares, opostos pelo vértice.

Medida dos ângulos. Uso do transferidor.

Paralelas e perpendiculares; problemas gráficos sobre seu traçado.

Triângulos: alturas, medianas, e bissetrizes; soma dos ângulos internos e externos.

Estudo sucinto dos quadriláteros.

Noções sobre figuras semelhantes; escala.

Medida indireta das distâncias.

Razões entre lados de um triângulo retângulo. Seno, co-seno e tangente de ângulo agudo. Uso de tabelas de senos, co-senos e tangentes naturais.

\section{II - Aritmética e Álgebra}

Noção de função de uma variável independente. Representação gráfica.

Estudo das funções $\mathrm{y}=\mathrm{ax}$ e $\mathrm{y}=\mathrm{a} / \mathrm{x}$; exemplos.

Proporções e suas principais propriedades.

Resolução de problemas sobre grandezas proporcionais. Porcentagens, juros, desconto (comercial), divisão proporcional, câmbio.

Equações do $1^{\circ}$ grau com uma incógnita. Problemas. Interpretação das soluções negativas.

Sistemas de equações do $1^{\circ}$ grau com duas incógnitas. Problemas.

Representação gráfica da função linear de uma variável. Resolução gráfica de um sistema de duas equações com duas incógnitas.

Divisão algébrica. Expoente zero. Expoente negativo.

Decomposição em fatores.

Frações algébricas. Simplificações (VECHIA e LORENZ, 1998, p. 336, grifos nossos).

Ao confrontar os programas de Matemática de 1931 com os de 1930, levou-se em consideração as colocações de Rocha (2001), ao afirmar que não houve mudanças significativas nas duas séries, uma vez que a Reforma Francisco Campos "apropriou-se das inovações que vinham sendo implementadas de forma paulatina, desde 1929, no Colégio Pedro II" (ROCHA, 2001, p. 237).

Desse modo, os conteúdos estudados na disciplina Matemática para o ano de 1931, mantinham algumas semelhanças com os programas dos anos de 1929 e 1930, embora o seu currículo conservasse uma densidade no número de assuntos aplicados nas aulas. Logo, a quantidade de pontos a serem ensinados durante esses anos totalizavam: 26 na $1^{\text {a }}$ série de 1929; 23 na $1^{\mathrm{a}}$ série e 17 na $2^{\mathrm{a}}$ série do ano de 1930; e no ano de 1931,17 e 18 na $1^{\mathrm{a}}$ e $2^{\mathrm{a}}$ séries, respectivamente.

Já os conteúdos das $3^{\mathrm{a}}$ e $4^{\mathrm{a}}$ séries se dividiam em duas partes: a primeira em Aritmética e Álgebra e a segunda em Geometria, integrados e aplicados, paulatinamente, mas, mesmo assim, os assuntos aplicados nas aulas ainda permaneciam densos, totalizando, em cada série, respectivamente, 18 e 19 pontos a serem ensinados.

\section{TERCEIRA SÉRIE}

3 horas

\section{I - Aritmética e Álgebra}

Equações e problemas de $1^{\circ}$ grau com uma ou mais incógnitas.

Desigualdade do $1^{\circ}$ grau. 
Potências e raízes.

Estudo das funções $\mathrm{y}=\mathrm{xm}, \mathrm{y}=1 / \mathrm{xm}$ e $\mathrm{y}=\mathrm{Vx}$; representação gráfica.

Cálculo dos radicais. Expoentes fracionários.

Trinômio do $2^{\circ}$ grau.

Equação do $2^{\circ}$ grau. Resolução gráfica; resolução analítica. Discussão: propriedades das raízes.

Desigualdades do $2^{\circ}$ grau.

\section{II - Geometria}

Conjunto de proposições fundamentais que servem de base à Geometria dedutiva. Noções sobre deslocamentos elementares no plano; translação e rotação de figuras. Simetria.

Estudo de triângulos.

Estudo dos polígonos; soma dos ângulos internos e externos.

Noção e exemplares de lugar geométrico.

Círculo; propriedades dos arcos e cordas. Tangente e normal.

Medidas dos ângulos.

Linhas proporcionais; linhas proporcionais no triângulo.

Semelhança; homotetia.

Relações métricas no triangulo.

Relações métricas no círculo. Média proporcional.

\section{QUARTA SÉRIE}

3 horas

\section{I - Aritmética e Álgebra}

Equações biquadradas e equações irracionais.

Problemas do $2^{\circ}$ grau; discussão.

Progressão aritmética. Propriedades. Interpolação.

Progressão geométrica. Propriedades. Interpolação.

Estudo da função exponencial.

Logaritmos; propriedades. Uso das tábuas.

Régua logarítmica.

Juros compostos; unidades.

\section{II - Geometria}

Polígonos regulares; relação métrica nos polígonos regulares.

Medida da circunferência; cálculo de pi (método dos perímetros).

Áreas equivalentes; relação entre áreas de figuras semelhantes.

Retas e planos no espaço.

Ângulos poliedros. Triedros suplementares.

Os de Prisma e pirâmides.

Cilindro e cone.

Esfera. Seções planas. Pólos; plano tangente; cone e cilindro circunscritos.

Noção sobre geração e classificação das superfícies; superfícies regradas, de revolução, desenvolvíveis.

As funções circulares; relações entre essas funções. Gráficos.

Expressões da tangente, cotangente, secante e co-secante em função do seno e co-seno e tangente da soma de dois ângulos, do dobro de um ângulo, da metade de um ângulo (VECHIA e LORENZ, 1998, p. 337, grifos nossos).

Os conteúdos da $5^{\text {a }}$ série se apresentavam em conjunto, numa total integração. Contudo, os assuntos a serem ensinados reafirmavam o caráter enciclopédico do novo 
programa de Matemática, demonstrando, assim, sua densidade por meio de um total 12 pontos que deveriam ser aplicados.

\section{QUINTA SÉRIE}

3 horas

\section{Aritmética, Álgebra e Geometria}

Resolução de triângulos retângulos, prática das tábuas de logaritmos.

Casos simples de resolução de triângulos obliquângulos.

Noções de análise combinatória.

Binômio de Newton (caso de expoente inteiro e positivo).

Derivada de um polinômio inteiro em $\mathrm{x}$.

Noção de limite. Derivada de x. Derivada de seno de x, co-seno de x, tangente de $\mathrm{x}$ e cotangente de $\mathrm{x}$.

Interpretação geométrica da noção de derivada. Aplicação da noção de derivada ao estudo da variação de algumas funções simples.

Processos elementares de desenvolvimento em série; convergência de uma série.

Desenvolvimento em série do seno, co-seno e tangente.

Problema inverso da derivação. Primitivas imediatas. Aplicação ao cálculo de certas áreas.

Volumes do prisma e do cilindro; da pirâmide, do cone e dos respectivos troncos. Volume da esfera e suas partes.

Estudo sucinto das seções cônicas (VECHIA e LORENZ, 1998, p. $337-$ 338 , grifos nossos)

O programa de Matemática do Curso Fundamental vinha acompanhado das Instruções Pedagógicas para o ensino de Geometria, Aritmética e Álgebra, deliberadas pela Portaria Ministerial de 30 de junho de 1931.

No estudo da Geometria o aluno partiria de um curso propedêutico de Geometria intuitiva e experimental, procurando se familiarizar "com as idéias fundamentais relativas às figuras geométricas, no plano e no espaço, sob o ponto de vista da forma, da extensão e da posição". Dessa maneira, objetiva-se "exercitar a percepção e a imaginação espaciais; desenvolver a faculdade de abstração; despertar o interesse pela estimativa e a medição, bem como pelo uso da régua, do compasso, dos esquadros, do transferidor, e pela construção de modelos". Assim, esse plano de ensino permitiria que a mocidade da época, antes do término da parte propedêutica aplicasse as deduções exatas das relações descobertas, para, posteriormente, estabelecer embasamento lógico dedutivo instigado pela necessidade de uma demonstração rigorosa. Neste sentido, dever-se-ia estar atento ao enunciado das proposições para melhor demonstrar e aplicar o que se pede; compreender e apreciar o raciocínio dedutivo, além de valorizar a exposição clara e sucinta "do encadeamento lógico das idéias e da memória matemática”. Na segunda série começariam as primeiras noções sobre Trigonometria, mediante aplicação das propriedades elementares das funções trigonométricas, importantes nas resoluções de problemas sobre triângulos, retângulos, no "emprego de tabelas que forneçam diretamente, com três ou quatro decimais, os valores de tais funções para ângulos que variam de grau em grau" (BRASIL, 2005). 
$\mathrm{Na}$ parte de Aritmética desenvolvia-se o discernimento perceptivo dos valores numéricos, além da habilidade dos cálculos. Na aplicação dos exercícios utilizava-se constantemente o Cálculo, oral ou escrito, mas o aprendizado do cálculo mental sobressaíase aos demais. A princípio as operações sobre frações seriam explicadas intuitivamente, através do fracionamento de objetos ou de grandezas geométricas. Desde o início se aprendia a representação geométrica das séries numéricas, tornando fácil o aprendizado da representação gráfica das funções empíricas e alcançar, posteriormente, o estudo gráfico das funções analíticas. Na primeira série eram explicadas as noções de divisibilidade, número primo, decomposição em fatores, a formação de mínimo múltiplo comum e do máximo divisor comum, a fim de despertar no aluno a aplicação de métodos ágeis capazes de operar, quanto possível, mentalmente despreocupados com o formalismo ou rigor dedutivo, evitando, assim, a mecanização dos processos.

No ensino da Álgebra os conceitos e processos matemáticos seriam apresentados paulatinamente, dos mais fáceis aos mais complexos, por sucessivos graus e correlacionados com a Geometria intuitiva. Desse modo, os números literais e os polinômios de primeiro grau seriam introduzidos atrelados "com as noções de distância, de perímetro, de ângulo, e de medida da circunferência, ao passo que as avaliações de superfície fornecerão sentido real às expressões quadráticas e o cálculo dos volumes ao das cúbicas". A noção de número qualificado se apoiava no conhecimento dos segmentos dirigidos e outras grandezas mensuráveis. O entendimento sob equação surgiria naturalmente, durante a "resolução de problemas simples de aritmética, com uma só incógnita e do $1^{\circ}$ grau" (BRASIL, 2005). A inclusão do método infinitesimal permitia ao aluno o conhecimento do mais importante recurso matemático durante o estudo do cálculo das derivadas, levando em consideração as razoáveis exigências do rigor matemático e as necessidades práticas por meio do auxílio das explicações geométricas e intuitivas.

Deste modo, a intenção do programa de Matemática durante a Reforma Francisco Campos era correlacionar todos os seus ramos. Cada matéria seria abordada a partir de uma introdução intuitiva até alcançar o raciocínio abstrato. Como já foi dito, os conteúdos de ensino vinham acompanhados de Instruções Pedagógicas, cuja aplicação constituía uma novidade à época, por demonstrar a forma de ensinar Matemática segundo sua finalidade e outras competências.

O ensino da Matemática tem por fim desenvolver a cultura espiritual do aluno pelo conhecimento dos processos matemáticos, habilitando-o, ao mesmo tempo, à concisão a ao rigor do raciocínio pela exposição clara do pensamento em linguagem precisa.

Além disso, para atender ao interesse imediato de sua utilidade ao valor educativo dos seus métodos, procurará, não só despertar no aluno a capacidade de resolver e agir, com presteza e atenção, como ainda favorecer-lhe o desenvolvimento da faculdade de compreensão e de análise das relações quantitativas e especiais, necessárias às aplicações nos diversos domínios da vida prática e à interpretação exata e profunda do mundo objetivo (BRASIL, 2005).

Essas instruções traziam consigo as inovações defendidas por Euclides Roxo em prol do movimento renovador dos estudos matemáticos, apoiados na "predominância essencial do ponto de vista psicológico", "dependência da escolha da matéria a ensinar em relação ao conjunto das demais disciplinas" e "subordinação da finalidade do ensino às diretrizes culturais da época" (ROCHA, 2001, p. 171-172). 
Para tanto, a Matemática compreendia "um conjunto harmônico cujas partes estão em viva e íntima correlação", e a unificação dos seus ramos não deveriam "estabelecer barreiras intransponíveis, que impeçam o estudante de perceber as conexões entre aquelas disciplinas". Sua integração partiu do conceito de função "apresentada, a princípio, intuitivamente e desenvolvida, nas séries sucessivas do curso, de modo gradativo, tanto sob a forma geométrica como sob a analítica" (BRASIL, 2005).

Entre outros objetivos, o ensino da função preparava o aluno para incluir "na $5^{a}$ série o ensino de noções fundamentais e iniciais do cálculo das derivadas, tendo-se não só em vista a sua aplicação a certas questões, geralmente tratadas em matemática elementar por processos artificiais", mas também nos problemas de Mecânica e Física (BRASIL, 2005).

Outro ponto importante das instruções refere-se ao emprego da História da Matemática para "aumentar o interesse do aluno", por meio "de ligeiras alusões a problemas clássicos e curiosos aos fatos capitais da história da Matemática, bem como à biografia dos grandes vultos desta ciência" (BRASIL, 2005).

Além de expor os objetivos e ideias concernentes à Matemática do Curso Fundamental, as instruções metodológicas também forneciam orientações individuais aos ramos dessa disciplina.

$\mathrm{Na}$ análise de Rocha (2001), o autor ressaltou a importância do ensino da Geometria "precedido de um curso propedêutico de iniciação geométrica". Nas suas palavras, a Geometria Dedutiva não foi abandonada, mas cercada de certos cuidados, principalmente por enfatizar o caráter dedutivo da Geometria Plana. Informou também que segundo as instruções a Trigonometria passaria a fazer parte "da geometria e não como ramo isolado da matemática" (ROCHA, 2001, p. 173).

Como resultado das análises, verificou-se que o programa de Matemática implementado pela Reforma Francisco Campos, na aplicação dos seus conteúdos, interagia entre seus ramos, de forma paulatina até a $5^{\mathrm{a}}$ série, atingindo um conjunto. Descritas de forma geral e sem exemplos práticos sobre a fusão das Matemáticas, as instruções metodológicas se apresentavam diferentes daquelas que foram inseridas nos programas do Colégio Pedro II, nos anos de 1929 e 1930.

No final das instruções, apontou-se uma contradição sobre a enumeração da matéria de cada ramo. Segundo elas, "a ordem em que é enumerada a matéria de cada série não é obrigatória; serve apenas para mostrar como se podem subordinar os programas dos cursos às diretrizes metodológicas aqui estabelecidas" (BRASIL, 2005).

Dessa maneira, também se levou em consideração as afirmações de Rocha (2001), quando diz que:

\footnotetext{
Até mesmo visualmente, essa maneira de apresentação dos programas ia de encontro às inovações que vinham sendo implementadas desde 1929 no Colégio Pedro II, em que se pretendia muito mais uma reforma dos métodos de ensino do que propriamente uma mudança dos programas. Assim, essa decisão de Euclides Roxo pode ter dificultado a compreensão, por parte de muitos professores, do efetivo intuito da reforma (ROCHA, 2001, p. 175).
}

Em suma, a presença marcante da disciplina Matemática em todas as séries do currículo secundário do Colégio Pedro II durante o ano de 1931, atendia aos ditames das instruções metodológicas deliberadas pela Reforma Francisco Campos. Seus conteúdos 
estabeleciam uma correlação com Aritmética, Álgebra e Geometria fazendo com que o ensino adquirisse uma noção de função, já que os ensinamentos matemáticos se apresentavam inicialmente de forma intuitiva e em seguida desenvolvidos gradualmente, de maneira geométrica e analítica.

Assim, este artigo contribui nas pesquisas sobre a História da Educação, principalmente para as investigações sobre a história do ensino da Matemática no Brasil por meio da ação da Reforma Francisco Campos, além de instigar futuros estudos que pautam suas temáticas no ensino secundário, na História das instituições e disciplinas escolares.

\section{REFERÊNCIAS}

ALVAREZ, Tana Giannassi. A Matemática da Reforma Francisco Campos em ação no cotidiano escolar. Dissertação (Mestrado em Educação Matemática). PUC/SP. São Paulo, 2004.

BITTENCOURT, Circe Fernandes. Ensino de História: fundamentos e métodos. São Paulo: Cortez, 2004.

BOURDIEU, Pierre. Pierre Bourdieu: sociologia. ORTIZ, Renato Organizador (da coletânea), São Paulo: Ática, 1983.

BRASIL. Decreto $\mathbf{n}^{\circ}$. 19.890. Rio de Janeiro, 18 de abril de 1931: Dispõe sobre a organização do ensino secundário. Disponível em: < http://www.histedbr.fae.unicamp.br/>> acessado em 01/02/2009.

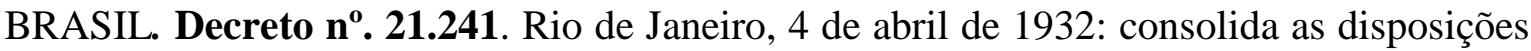
sobre a organização do ensino secundário e deliberou outras providências.Disponível em: << http://www.histedbr.fae.unicamp.br/>> acessado em 01/02/2009.

BRASIL. Decreto n ${ }^{\circ}$. 19.890, de 18 de abril de 1931 - Exposição de Motivos. Rio de Janeiro, 10 de abril de 1931. A matemática do Ginásio: livros didáticos e as reformas Campos e Capanema. São Paulo: GHEMAT, CD-ROM, 2005.

CHERVEL, André. História das disciplinas escolares: reflexões sobre um campo de pesquisa. In: Teoria e Educação, n. 2, 1990, p.177-229.

DASSIE, Bruno Alves. A matemática do curso secundário na Reforma Gustavo Capanema. Dissertação (Mestrado em Matemática Aplicada). PUC/RJ. Rio de Janeiro, 2001.

HORTA, José Silvério Baia. O hino, o sermão e a ordem do dia: regime autoritário e a educação no Brasil (1930-1945). Rio de janeiro: Editora UFRJ, 1994.

MIRANDA, Marilena Moussa. A experiência norte-americana de fusão da Aritmética, Álgebra e Geometria e sua apropriação pela educação matemática brasileira. 
Dissertação (Mestrado em Educação Matemática). Pontifícia Universidade Católica de são Paulo. São Paulo, 2003.

MORAES, Maria Célia Marcondes de. Francisco Luís da Silva Campos. In: FÁVERO, Maria de Lourdes de Albuquerque; BRITTO, Jader de Medeiros (orgs.). Dicionário de educadores no Brasil: da Colônia aos dias atuais. Rio de Janeiro: UFRJ/MEC-INEP, 2002, p. 195- 200.

MOREIRA, Antônio Flavio Barbosa. Currículos e Programas no Brasil. Campinas: Papirus, 1990.

NUNES, Clarice. O "velho" e "bom" ensino secundário: momentos decisivos. In: SAVIANI, Dermeval; CUNHA, Luiz Antônio. CARVALHO, Maria Marta Chagas de (orgs.). Revista Brasileira de Educação - 500 anos de Educação Escolar. Campinas: Autores Associados/ANPED, nº. 14, mai/jun/jul/ago, 2000, p. 35-60.

OTONE E SILVA, Maryneusa Cordeiro A Matemática do Curso Complementar da Reforma Francisco Campos. Dissertação (Mestrado em Educação Matemática). PUC/SP. São Paulo, 2006.

ROCHA, José Lourenço da. A Matemática do curso secundário na Reforma Francisco Campos. Dissertação (Mestrado em Matemática). PUC/ RJ. Rio de Janeiro, 2001.

SAVIANI, Dermeval; ALMEIDA, Jane Soares de; SOUZA, Rosa Fátima de. VALDEMARIN, Vera Teresa. O legado educacional do século XX no Brasil. Campinas: Autores Associados, 2004.

SILVA, Geraldo Bastos. A educação secundária: perspectiva histórica e teoria. São Paulo: Companhia Editora Nacional, 1969.

SOUZA, Rosa Fátima de. História da organização do trabalho escolar e do currículo no Século XX: (ensino primário e secundário no Brasil). São Paulo: Editora Cortez, 2008.

TAVARES, Jane Cardote. A Congregação do Colégio Pedro II e os debates sobre o ensino de matemática. Dissertação (Mestrado em Educação Matemática). PUC/SP. São Paulo, 2002.

VALENTE, Wagner Rodrigues. A disciplina matemática: etapas históricas de um saber escolar no Brasil. In: OLIVEIRA, Marcus Aurélio Taborda, RANZI, Serlei Maria Fischer (org). História das disciplinas escolares: contribuições para o debate. Bragança Paulista: EDUSF, 2003, p. 217-254.

VALENTE, Wagner Rodrigues. Euclides roxo e a modernização do ensino da matemática no Brasil. Brasília: Editora Universidade de Brasília, 2004a.

VALENTE, Wagner Rodrigues. O nascimento do ginásio. São Paulo: Annablume: FAPESP, 2004b. 
VECHIA, Ariclê. LORENZ, Karl Lorenz. Programa de ensino da escola secundária brasileira: 1850-1951. VECHIA, Ariclê. LORENZ, Karl Lorenz (org). Curitiba: Ed. do Autor, 1998.

VEIGA, Cynthia Greive. História da Educação. São Paulo: Ática, 2007.

WARDE, Mirian Jorge. Americanismo e Educação: a fabricação do "homem novo". Projeto de Pesquisa. PUC/SP, 2000- atual, p. 1-23.

WERNECK, Arlete P. Terra. Euclides Roxo e a Reforma Francisco Campos: a gênese do primeiro programa de ensino de matemática brasileiro. Dissertação (Mestrado em Educação Matemática). PUC/SP. São Paulo, 2003.

\footnotetext{
${ }^{1}$ Mestra em Educação pela Universidade Federal de Sergipe, membro do Grupo de Pesquisa História das Disciplinas Escolares: história, ensino e aprendizagem (GPDEHEA) e licenciada em Matemática. suelycristinas@yahoo.com.br

${ }^{2}$ Natural de Dores do Indaiá, Minas Gerais, nasceu no dia 18 de novembro de 1891. Cursou Direito entre os anos de 1910 e 1914. No ano de 1918 tornou-se professor substituto na cadeira de Direito Público Constitucional. Ingressou na carreira política entre os anos de 1926 a 1947 nos seguintes cargos: Deputado Federal por Minas Gerais (1926-1930), Ministro da Educação e Saúde Pública (1930-1932), Consultor Geral da República (1933-1937) e, finalmente, Ministro da Justiça (1937-1941). Mais informações ver Moraes (2002, p. 195-200).

${ }^{3}$ Para maior esclarecimento consultar Veiga (2007, p. 217-225).

${ }^{4}$ Nasceu na cidade de Aracaju, Sergipe, no dia 10 de dezembro de 1890. Bacharelou-se em 1909, no Internato do Colégio Pedro II. Em 1915, iniciou sua carreira docente como professor substituto de Matemática nessa instituição. Tornou-se catedrático em 1919 e diretor do Externato do Colégio Pedro II em 1925. Mais informações consultar Miranda (2003, p. 67-69).

${ }^{5}$ Sobre o assunto ver Tavares (2002, p. 85-130).

${ }^{6}$ O Curso Complementar preparava os alunos para o curso superior, em caráter de especialização. Logo, o Curso Complementar de Matemática seria necessário para o ingresso nas Escolas Militares e Politécnicas.

${ }^{7} \mathrm{O}$ termo modelo melhor se explica nas palavras de Warde (2000) quando diz que, representam "[...] constructos de um imaginário que lhes confere forma e conteúdo com um forte teor racional e um sentido prático: trata-se de ferramentas para contendas na arena política; para concorrências pelo controle do mercado; para disputas no campo educacional e assim por diante" (WARDE, 2000, p. 4).

${ }^{8}$ Termo empregado em lugar de conhecimento científico por Chervel (1990, p. 180).
}

Recebido em julho de 2011

Aprovado em abril de 2012 